\title{
CLINICAL SPECTRUM OF HYPONATRAEMIA IN MEDICINE ICU OF DMCH
}

\author{
Umesh Chandra Jha ${ }^{1}$, Manish Kumar ${ }^{2}$
}

${ }^{1}$ Associate Professor, Department of Medicine, Darbhanga Medical College and Hospital, Laheriasarai.

${ }^{2} 3^{\text {rd }}$ Year Postgraduate Resident, Department of Medicine, Darbhanga Medical College and Hospital, Laheriasarai.

\section{ABSTRACT}

\section{BACKGROUND}

Hyponatraemia is one of the most common disorder of electrolytes encountered in a clinical setting of Intensive Care Unit. There has been no consensus on optimal management of hyponatraemia. Despite knowledge of hyponatraemia being a common disorder, high mortality among the patients is secondary to the underlying medical conditions rather than the degree of hyponatraemia.

The objective of this study is to assess the incidence, aetiological factors, clinical manifestations, treatment outcomes and complications of hyponatraemia in Medical ICU of Darbhanga Medical College, Laheriasarai.

\section{MATERIALS AND METHODS}

This study was a descriptive study. Admitted patients whose serum electrolytes had been estimated in the ICU of Dept. of Medicine, Darbhanga Medical College, Laheriasarai in the period from 01 Dec. 2014 to 31 July 2016, were evaluated. Patients with a serum sodium concentration $<135 \mathrm{mEq} / \mathrm{L}$ during the admission period were included in the study.

\section{RESULTS}

Out of 614 patients admitted in ICU, 102 patients developed hyponatraemia (17.58\% incidence). Study included 100 patients. Symptoms included lethargy (33\%), postural dizziness and abnormal behaviour. Most common aetiological factor came out to be liberal use of diuretics (35\%) vomiting, gastroenteritis and febrile illness. Pre-existing illnesses associated with hyponatraemia were maximum with previous history of hypertension (58\%), diabetes (40\%) and chronic kidney disease (18\%). Major treatment modality included normal saline (64\%) either for treatment or as a part of fluid therapy, salt supplements and water restriction. One patient developed treatment related complications. A total of 19 patients died in this study including 7 patients with severe hyponatraemia.

\section{CONCLUSION}

The possible cause of hyponatraemia should always be sought as outcome in severe hyponatraemia, is governed by aetiology and not by the serum sodium level. Treatment of severe symptomatic hyponatraemia with hypertonic saline is safe if recommendation for the rate of correction of hyponatraemia is strictly followed.

\section{KEYWORDS}

Hyponatraemia, Medical ICU, Incidence, Objectives.

HOW TO CITE THIS ARTICLE: Jha UC, Kumar M. Clinical spectrum of hyponatraemia in medicine ICU of DMCH. J. Evolution Med. Dent. Sci. 2017;6(73):5257-5262, DOI: 10.14260/Jemds/2017/1141

\section{BACKGROUND}

Hyponatraemia is defined as a serum sodium level $<135$ $\mathrm{mEq} / \mathrm{L}$. An abnormal sodium level does not necessarily imply abnormal sodium balance, but can be due to abnormal water balance as well. Hyponatraemia, i.e. an excess of water in relation to the sodium in the extracellular fluid, is the most common electrolyte disorder in hospitalised patients and particularly so in the elderly.

It is important to recognise Hyponatraemia, because of the potential morbidity and mortality.

There is a lack of Indian data on clinical spectrum of hyponatraemia in ICU setting and treatment strategies to be adapted in various clinical studies, therefore we planned to

Financial or Other, Competing Interest: None.

Submission 11-08-2017, Peer Review 30-08-2017,

Acceptance 01-09-2017, Published 11-09-2017.

Corresponding Author:

Dr. Umesh Chandra Jha,

Associate Professor,

A. S. Memorial Hospital,

Behind Oriental Bank of India,

Benta, Laheriasara-846009, Bihar.

E-mail:dru.c.jha@gmail.com

DOI: $10.14260 /$ jemds/2017/1141

\section{(c) (i) $(9)$}

undertake this prospective followup study in hospitalised patients in Medicine ICU of Darbhanga Medical College, Laheriasarai.

\section{Physiology of Sodium and Water Regulation}

Sodium and potassium are the major cations in the ECF and ICF, respectively. Chloride and bicarbonate are the major accompanying anions in the ECF, and negative charges on organic molecules maintain electroneutrality with potassium in the ICF. Difference in cationic solute composition between these two compartments is maintained by a pump-leak mechanism involving the activity of $\mathrm{Na}+, \mathrm{K}+$-adenosine triphosphate (ATPase), operating in concert with cell membrane sodium and potassium conductance pathways.

\section{Hyponatraemia \\ Hyponatraemia is defined as a plasma $[\mathrm{Na}+]<135 \mathrm{mEq} / \mathrm{L}$. Hyponatraemia is the most commonly observed electrolyte imbalance in hospitalized patients, occurring in up to $1-6 \%$ of patients. ${ }^{(1,2)}$}

\section{Aetiology and Classification}

Hyponatraemia can be associated with low normal or high tonicity of the plasma and can be classified as

a. Hypotonic hyponatraemia. 
b. Non-hypotonic hyponatraemia:

I. Hypertonic hyponatraemia.

II. Isotonic hyponatraemia.

III. Pseudohyponatraemia.

Hyponatraemia with Normal or High Plasma Osmolality

a. Pseudohyponatraemia.

b. Hyponatraemia with a high plasma osmolality.

c. Post-transurethral resection of the prostate (post-TURP) syndrome.

\section{Hypo-Osmolar Hyponatraemia}

Hypovolaemic hyponatraemia- Total body water (TBW) decreases; total body sodium (TB Na+) decreases to a greater extent. May result from renal or non-renal causes of sodium loss, differentiated by measurement of urinary sodium. A decreased effective circulating volume stimulates the hypothalamic thirst centers and vasopressin release from the posterior pituitary gland, which cause hyponatraemia from free water accumulation.

\section{Causes of Hypovolaemic Hyponatraemia are}

1. Diuretics.

2. Cerebral salt wasting (CSW).

3. Gastrointestinal and third-space losses.

4. Salt-losing nephropathy.

5. Mineralocorticoid deficiency.

6. Osmotic diuresis.

Hypo-osmolar hyponatraemia- Total body sodium increases and TBW increases to a greater extent. It occurs in oedematous states such as congestive heart failure (CHF), hepatic cirrhosis, severe nephrotic syndrome as a result of a decrease in effective circulating volume leading to increased thirst and vasopressin levels. The increase in total body $\mathrm{Na}+$ is exceeded by the rise in total body water. The degree of hyponatraemia often correlates with the severity of the underlying condition and is therefore an important prognostic factor.

Normovolaemic hyponatraemia- TBW increases, while total sodium remains normal. Causes of normovolaemic hyponatraemia are -

1. SIADH.

2. Hypothyroidism.

3. Glucocorticoid deficiency.

4. Beer potomania.

5. Psychogenic polydipsia.

\section{Objectives}

To assess the incidence, aetiological factors, clinical manifestations, treatment outcomes and complications of hyponatraemia in Medical ICU of Darbhanga Medical College, Laheriasarai.

\section{MATERIALS AND METHODS}

A descriptive study was performed on all admitted patients whose serum electrolytes (Serum sodium) had been estimated in the ICU of Department of Medicine, Darbhanga Medical College, Laheriasarai, from 01 Dec 2014 to 31 July 2016, were included. Those patients with a serum sodium concentration $<135 \mathrm{mEq} / \mathrm{L}$ at any point during the admission were included in the study.

\section{Data Collection}

For all patient's clinical and demographic detail, final diagnosis, investigations and management were recorded onto a standard data collection sheet as per the study proforma.

\section{Statistical Analysis}

Data were recorded on a predesigned proforma and managed in a Microsoft Excel spreadsheet and analysed. Descriptive statistics, i.e. mean and standard deviation have been calculated for the continuous variables. Categorical variables are expressed as percentages.

\section{RESULTS}

\section{Incidence}

A total of 7562 patients were admitted to the medical emergency and wards, out of which 614 patients were transferred to the ICU of Dept. of Medicine, Darbhanga Medical College between the period from 01 Dec 2014 to 31st July 2016; 102 patients out of 614 the admitted patients in ICU developed hyponatraemia giving an incidence of $17.58 \%$.

\section{Clinical Profile}

\section{Age Distribution}

The maximum numbers of patients were in the age group of $60-70$ yrs. (24\%); $65 \%$ of the total 100 patients were between the age of 50 and $80 \mathrm{yrs}$. The youngest patient was 19 years, while oldest patient was 86 years old. Mean age was 58.79 years.

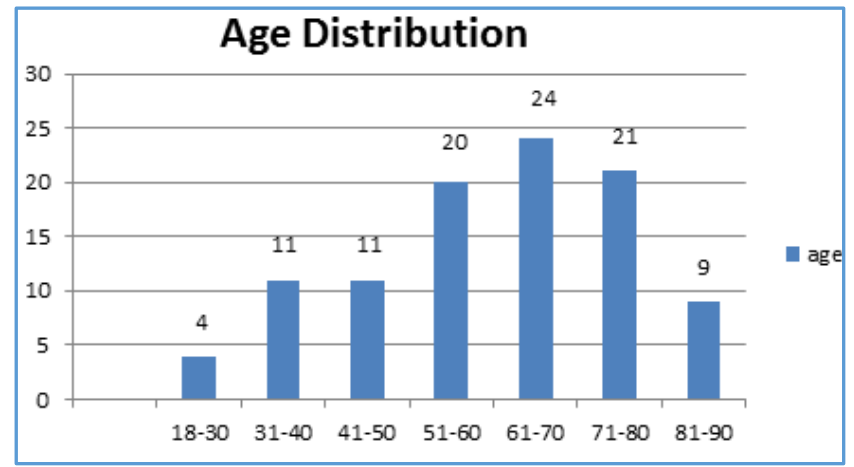

Graph I

\section{Sex Distribution}

There were $39 \%$ females and $61 \%$ males out of total 100 patients in this study.

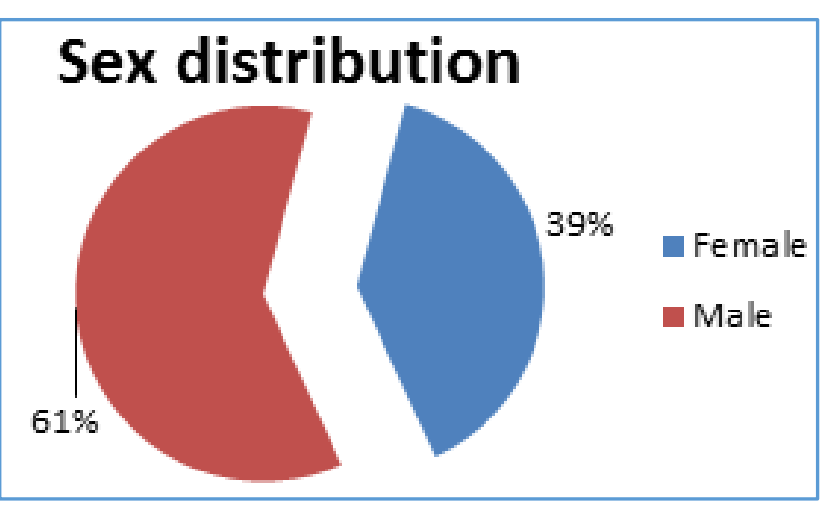

Graph II 


\section{Symptoms}

Majority (43\%) of the patients were asymptomatic at presentation. Among symptomatic cases (57\%), several patients had combination of symptoms. Thirty three percent patients had lethargy, $19 \%$ patients had altered sensorium due to hyponatraemia and $28 \%$ patients had postural dizziness as one patient had seizure due to hyponatraemia.

\section{Correlation of Symptom and Level of Serum Sodium}

Total of $43(43 \%)$ patients were asymptomatic with documented hyponatraemia. Among them 7 patients had severe hyponatraemia and 39 patients had moderate hyponatraemia. The lowest serum sodium level among asymptomatic patient was $116 \mathrm{mEq} / \mathrm{L}$ (Mean- $123.4 \mathrm{mEq} / \mathrm{L}$, SD- $4.9 \mathrm{mEq} / \mathrm{L})$.

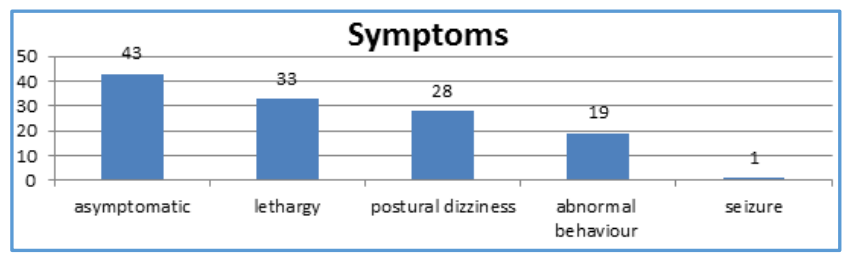

Graph III

\section{Pre-Existing Illnesses}

Fifty two (52\%) patients had Hypertension, 40 (40\%) patients had Diabetes Mellitus, 18 (18\%) patients had Chronic Kidney Disease (CKD), 8 (8\%) patients had Congestive Heart Failure (CHF), 7 (7\%) patients had Liver Disease and 5 (5\%) patients had Hypothyroidism as shown in Graph - IV.

Among 52 patients of HTN 13 had coexisting CKD, 33 with Diabetes, 6 had CHF and 3 had Hypothyroidism and Liver Disease as shown in Graph - IV.

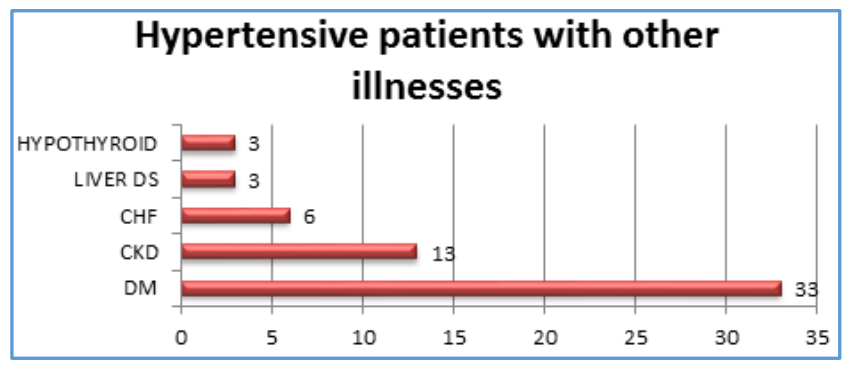

Graph IV

Out of 40 diabetic patients 33 had concomitant hypertension, 11 had CKD, 5 had CHF and 2 had hypothyroidism as shown in Graph - V.

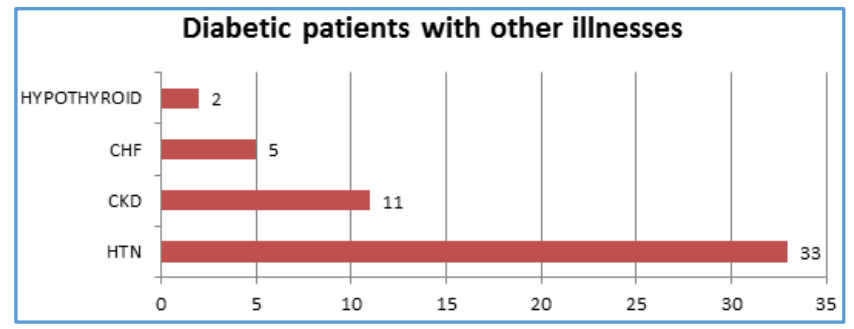

Graph V

\section{Aetiology of Hyponatraemia}

Sixty-five patients in this study had hypo-osmolar hyponatraemia, 31 patients had normal serum osmolality and 4 patients had hyperosmolar hyponatraemia.

Diuretic use was the most common cause of hyponatraemia in this study; 35 (35\%) patients were taking diuretics; 15 patients were on thiazides.

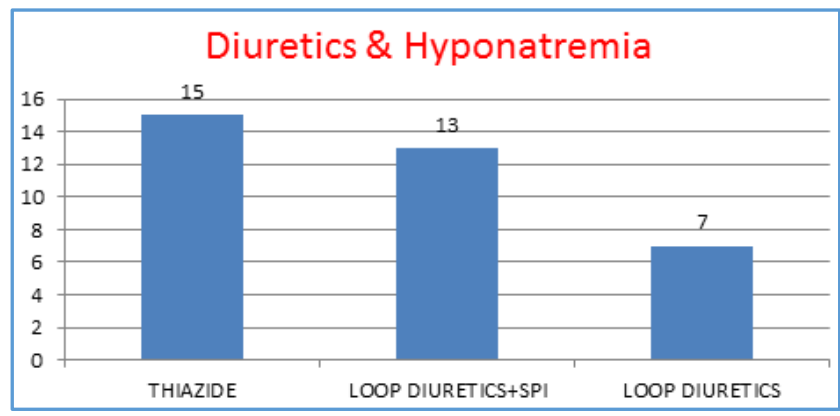

Graph VI

Vomiting was the second most common cause of hyponatraemia after diuretic use, present in 29 patients in this series. In 19 patients, hyponatraemia was due to renal disorder, 17 patients had pre-existing CKD. Other causes of hyponatraemia were depicted in Graph - VII.

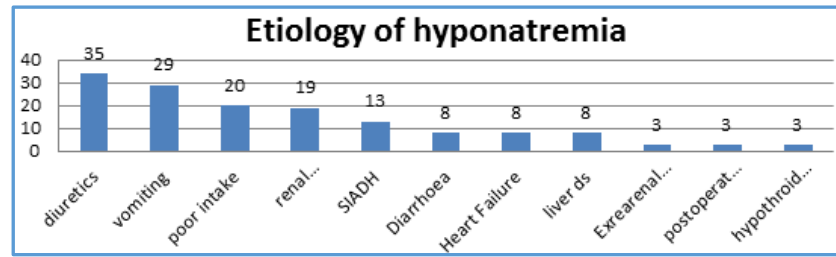

Graph - VII

In 57 patients there was single aetiology, while in 43 patients more than one contributory factors for hyponatraemia were responsible. Out of these 43 patients 37 patients had 2 contributory factors, 5 patients had 3 contributory factors and 1 patient had 4 contributory factors for hyponatraemia. Distribution of single aetiology of hyponatraemia is depicted below.

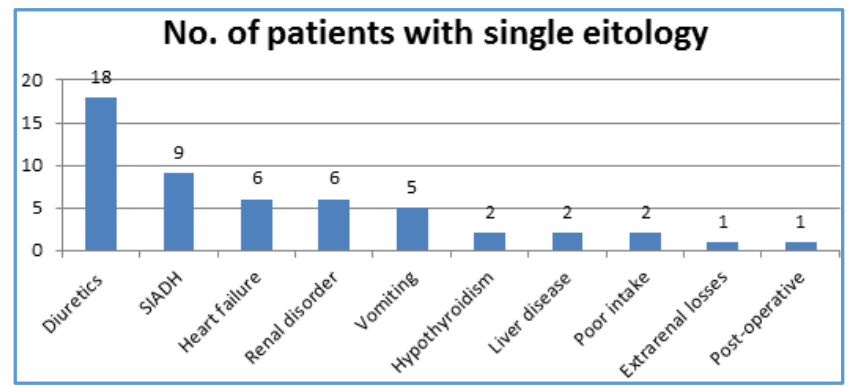

Graph VIII

Spectrum of severe hyponatraemia- 31 patients in this study had severe hyponatraemia, 69 patients had mild or moderate hyponatraemia.

Diuretic use was the most common aetiology associated with severe hyponatraemia in 13 patients. Other causes associated with severe hyponatraemia were vomiting which 
was present in 8 patients, renal disorders in 6 of them, heart failure in 5 patients, liver disorders in 5 patients and SIADH in another 5 patients depicted in graph below.

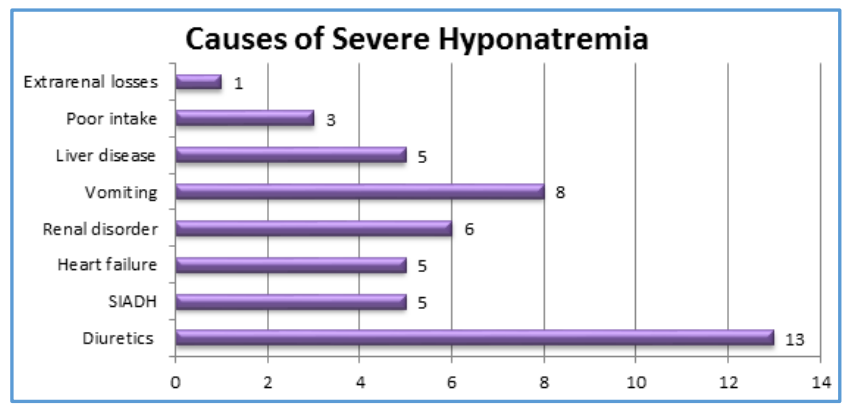

Graph IX

\section{Treatment}

\section{Oral Sodium Chloride Supplementation}

Oral sodium chloride supplementation was given in 36 patients. All the patients receiving hypertonic saline were given oral sodium chloride supplementation after symptomatic improvement and when oral intake could be resumed.

\section{Normal Saline $(0.9 \% \mathrm{NaCl})$}

Normal saline was given in 64 patients either for correction of hyponatraemia or as a part of fluid therapy.

\section{Hypertonic Saline}

$3 \%$ saline was used only for severe hyponatraemia patients or those with neurological symptoms.(3,4) Total 12 patients required hypertonic saline infusion.

\section{Diuretics}

25 patients were given loop diuretics for promoting free water excretion, which included patients of dilutional hyponatraemia (CHF, cirrhosis of liver, renal disorder) and patients with SIADH.

\section{Water Restriction}

Fluid restriction equal to urine output of previous 24 hours was advised in 44 patients either for correction of hyponatraemia or as a part of treatment of the basic disease as in CHF or CKD.

The various strategies adopted for the patients for correction of hyponatraemia has been summarised in Graph-XI.

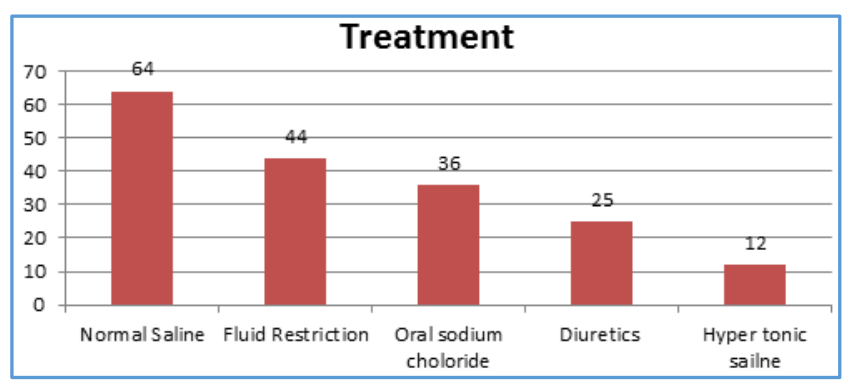

Graph $X$

\section{Potassium Replacement}

Total 13 patients developed hypokalaemia due to comorbid conditions like vomiting and diarrhoea or due to diuretic use. These patients were given oral potassium supplements.

The aim was to correct the serum sodium levels gradually by increasing sodium levels at $8-10 \mathrm{mEq} / \mathrm{L} /$ day. This aim was achieved in most of the patients.

\section{Complications of Treatment of Hyponatraemia}

One patient of severe hyponatraemia during the study had a rare renal salt wasting state. The patient was treated with hypertonic saline for severe hyponatraemia (serum sodium $113 \mathrm{mEq} / \mathrm{L}$ ) for two days outside the hospital. However, there was no improvement in the clinical status of the patient and hyponatraemia persisted despite treatment with hypertonic saline.

\section{Mortality}

Total of 19 (19\%) patients died during the study period from factors other than hyponatraemia. Most common cause was advanced cirrhosis of liver, present in 9 patients; 2 patients died due to urinary tract infection leading to sepsis. Other causes responsible for death were HIV infection with tubercular meningitis. Out of 31 patients of severe hyponatraemia in this study 7 patients died, a mortality of $22.58 \%$ among the patients of severe hyponatraemia.

\section{DISCUSSION}

\section{Clinical Manifestations of Hyponatraemia}

Clinical features of hyponatraemia are related to osmotic water shift leading to increased ICF volume, brain cell swelling and cerebral oedema. Severity of symptoms is dependent on magnitude of the fall in plasma level of sodium and the rapidity of the decrease:

a. Acute hyponatraemia- Hyponatraemia of $<2$ days duration. Nausea and malaise are the earliest findings, may be followed by headache, lethargy and eventually seizures, coma and respiratory arrest if the plasma sodium concentration falls below 115 to $120 \mathrm{mEq} / \mathrm{L}$.

b. Chronic hyponatraemia- Patients with chronic hyponatraemia appear to be asymptomatic despite a plasma sodium concentration that is persistently as low as 115 to $120 \mathrm{mEq} / \mathrm{L}$.

\section{Diagnosis of Hyponatraemia \\ History and Physical Examination}

History of fluid loss, signs of peripheral oedema and/or ascites, history consistent with one of the causes of SIADH such as small cell carcinoma or central nervous system disease, symptoms and signs suggestive of adrenal insufficiency or hypothyroidism.

\section{Laboratory Studies}

Plasma osmolality- low plasma osmolality $(<275 \mathrm{mOsm} / \mathrm{L})$, Urine osmolality- appropriate renal response to hypoosmolality is to excrete a maximally diluted urine (urine osmolality $<100 \mathrm{mOsm} / \mathrm{L}$ and specific gravity of $<1.003$ ), occurs in patients with primary polydipsia. If not it suggests impaired free water excretion due to the action of vasopressin on the kidney. 
Urine sodium concentration- It is used to discriminate between extrarenal and renal losses of $\mathrm{Na}+$ once it is established that hypovolaemic hyponatraemia is present.

\section{Other Investigations}

Plasma uric acid and urea concentrations- SIADH is frequently associated with hypouricaemia (Uric acid concentration $<4 \mathrm{mg} / \mathrm{dL}$ ) due to increased uric acid excretion in the urine. ${ }^{(5,6)}$

Fractional excretion of sodium $\left(\mathrm{FE}_{\mathrm{Na}}\right)$ - In patients with acute renal failure, the fractional excretion of sodium (FENa) provides a more accurate assessment of volume status than the urine sodium concentration; a FENa below 1 percent suggests effective volume depletion.

\section{Treatment of Hyponatraemia}

1. Mild asymptomatic hyponatraemia- requires no treatment.

2. Hypovolaemic asymptomatic hyponatraemia- $\mathrm{Na}+$ replenishment generally in the form of isotonic saline. Restoration of euvolaemic state abolishes the stimulus for secretion of AVP, allowing the excess water to be excreted. $(7,8)$

3. Hypervolaemic asymptomatic hyponatraemia-

a. Restriction of $\mathrm{Na}+$ and water intake.

b. Correction of hypokalaemia.

c. Promotion of water loss in excess of $\mathrm{Na}^{+}$- loop diuretics with oral salt to make for the proportionate amount of $\mathrm{Na}^{+}$loss in urine.

d. Restriction of dietary water to less than urine output.

4. Acute severe hyponatraemia-

a. Determination of the rate of correction.

b. Correction of the hypo-osmolality at the rate desired.

c. Correction of the underlying disorder.

Rate of correction of hyponatraemia depends upon the absence or presence of neurological dysfunction.

a. Asymptomatic patients- Plasma $\mathrm{Na}+$ should be raised by no more than 0.5 to $1.0 \mathrm{mEq} / \mathrm{L}$ per $\mathrm{h}$ and by not more than $10-12 \mathrm{mEq} / \mathrm{L}$ over the first $24 \mathrm{~h}$.

b. Severe symptomatic hyponatraemia (plasma $\mathrm{Na}+<110-$ $115 \mathrm{mEq} / \mathrm{L})$.

Hypertonic (3\%) saline should be infused to increase the plasma $\mathrm{Na}+$ by $1-2 \mathrm{mEq} / \mathrm{L}$ for the first 3 to $4 \mathrm{~h}$ or until the seizures subside. Once again, the total sodium concentration should be increased by not more than $10-12 \mathrm{mEq} / \mathrm{L}$ over the first $24 \mathrm{~h}$.

Increase in Plasma $\mathrm{Na}+$ by giving One Litre different Infusate can be calculated as

\begin{tabular}{|c|c|}
\hline 1. & Change in serum $\mathrm{Na}=$ Infusate $\left[\mathrm{Na}^{+}\right]-$Plasma $\left[\mathrm{Na}^{+}\right]$ \\
\hline 2. & $\begin{array}{c}\text { Total body water }+1 \\
\text { Change in serum } \mathrm{Na}=\text { Infusate }\left[\mathrm{Na}^{+}\right]+\text {Infusate }\left[\mathrm{K}^{+}\right]-\text {Plasma }\left[\mathrm{Na}^{+}\right]\end{array}$ \\
\hline & Total body water +1 \\
\hline
\end{tabular}

\section{Treatment of SIADH}

Acute SIADH

1. Fluid restriction.

2. Sodium supplementation.

\section{Chronic Asymptomatic Hyponatraemia}

1. Fluid restriction.

2. Lithium.

3. Demeclocycline.

4. Salt plus a loop diuretic.

5. Increased solute intake.

6. Urea.

7. Arginine vasopressin (AVP) receptor antagonists.

\section{CONCLUSION}

Following conclusions were drawn from this study and the results were compared to the previous studies.

1. Incidence of $\mathbf{1 7 . 5 8 \%}$ was a bit higher than the study done by Paniker G.I.* and Joseph S on "A prospective study on clinical profile of hyponatraemia in ICU hospitalised patients (4\%)" and comparable with study by Chatterjee et al on "descriptive study on hyponatraemia" (16.4\%).

2. Out of 100 patients studied Male sex was dominant with $61 \%$ having maximum numbers in between age of $60-70$ years. For this study, most common aetiological factor came out to be liberal use of diuretics (35\%), mostly thiazides (29\%). Other common causes were vomiting (29\%) and poor intake (20\%).

3. Attributable pre-existing illnesses associated with hyponatraemia were maximum with previous history of hypertension (52\%), other common being Diabetes (40\%) and Chronic Kidney Disease (18\%).

4. Majority patients (43\%) had asymptomatic clinical presentation. Among symptomatic patients, lethargy with drowsiness $(33 \%)$ was the most common presentation. Only one of the patients had seizure or coma due to hyponatraemia.

5. Major treatment modality included normal saline (64\%) either for treatment or as a part of fluid therapy. Next being salt supplements and water restriction.

6. One of the patients had treatment related complications. He was having severe hyponatraemia not improving to hypertonic saline. Patient developed Central Pontine Myelinolysis as characteristic bat's wing appearance in MRI of brain, which was presumably related to the hypertonic saline treatment.

7. Mortality was seen in patients of severe hyponatraemia. A total of 19 patients died from factors other than hyponatraemia. Most common cause was advanced cirrhosis of liver. Out of 31 patients of severe hyponatraemia in this study 7 patients died, thus giving a mortality of $22.58 \%$ among the patients of severe hyponatraemia.

Hyponatraemia is a common problem in hospitals, more so in critically ill ICU patients.

The possible cause of hyponatraemia should always be sought, as outcome in severe hyponatraemia is governed by aetiology and not by the serum sodium level. Treatment of severe symptomatic hyponatraemia with hypertonic saline is safe if recommendation for the rate of correction of hyponatraemia is strictly followed. 


\section{REFERENCES}

[1] William GF. The General and Cellular Basis of Medical Physiology. In: Review of Medical Physiology. 25th edn. McGraw Hill publication, 2015.

[2] Hall JE, Guyton AC. Urine Formation by the Kidneys: II. Tubular Reabsorption and Secretion. Text Book of Medical Physiology. $13^{\text {th }}$ edn. WB Saunders Company, 2016.

[3] Janicic N, Verbalis JG. Evaluation and management of hypo-osmolality in hospitalized patients. Endocrinol Metab Clin North Am 2003;32(2):459-81.

[4] Hannon MJ, Finucane FM, Sherlock M, et al. Clinical review: disorders of water homeostasis in neurosurgical patients. J Clin Endocrinol Metab 2012;97(5):1423-33.
[5] Agarwal SM, Agrawal A. A comparative study of the clinico-etiological profile of hyponatremia at presentation with that developing in the hospital. Indian J Med Res 2011;134:118-22.

[6] Robertson GL. Disorders of neurohypophysis. In Harrison's principles of internal medicine. Dennis KL, Anthony FS, Dan LL, (eds). 19th edn. Volume ii. McGraw Hill publication, 2015.

[7] Arthur GC, John HE. Regulation of extracellular fluid osmolarity and sodium concentration. Text Book of Medical Physiology. 13th edn. WB Saunders Company, 2016.

[8] Arthur GC, John HE. Renal mechanisms for blood and extracellular fluid volume control. Text Book of Medical Physiology. $13^{\text {th }}$ edn. WB Saunders Company, 2016. 